\title{
REPRODUCTIVE CHARACTERISTICS OF THE CAPTIVE MILKY STORK (MYCTERIA CINEREA) IN ZLIN ZOO, CZECH REPUBLIC
}

\author{
Zuzana Rečková1, Radek Filipčík ${ }^{1}$, Roman Horský², Vladimír Mikule1 \\ ${ }^{1}$ Department of Animal Breeding, Faculty of AgriSciences, Mendel University in Brno, Zemědělská 1, 61300 Brno, \\ Czech Republic \\ 2 ZOO and palace Zlín-Lešná, Lukovská 112, 76314 Zlín, Czech Republic
}

Link to this article: https://doi.org/10.11118/actaun.2021.055

Received: 1. 9. 2021, Accepted: 22. 11. 2021

To cite this article: REČKOVÁ ZUZANA, FILIPČÍK RADEK, HORSKÝ ROMAN, MIKULE VLADIMÍR. 2021. Reproductive Characteristics of the Captive Milky Stork (Mycteria cinerea) in Zlin Zoo, Czech Republic. Acta Universitatis Agriculturae et Silviculturae Mendelianae Brunensis, 69(6): 629-634.

\begin{abstract}
The limited range of Milky Stork in its natural habitat, as well as in under captivity, makes it difficult to learn more about it. This paper aimed to examine the breeding biology of Milky Stork raised in captivity in the Zlín-Lešná Zoo in the Czech Republic. By analyzing partial reproduction characteristic, we wanted to supplement the knowledge that is needed to ensure the necessary degree of reproduction of the Milky Stork in human care. The monitoring was carried out in the Zlín-Lešná Zoo and the following reproductive indicators were analysed: annual laying rate, size and weight of eggs laid, monitoring of egg weight loss during incubation, hatchability, and hatching weight. During the four years, a total of 23 eggs of the Milky Stork by one parent pair were evaluated. The average proportion of fertilised eggs over the whole period reached 56.5\%. The average eggs length was $65.7 \mathrm{~mm}$, the average eggs width was $47.0 \mathrm{~mm}$ and the average eggs weight was $79.7 \mathrm{~g}$. Average weight loss of eggs during their incubation was $8.4 \mathrm{~g}$. Average hatchability of all the laid eggs was 56.5\%. A total of 13 young Milky Storks were hatched during the observation period. Their average hatching weight was $55.7 \mathrm{~g}$. A total of five individuals were raised during the four years of observation. Knowledge in the field of reproduction is one of the basic prerequisites to give this species a chance to survive in the future, whether in the natural environment or human care.
\end{abstract}

Keywords: ciconiiformes, milky stork, mycteria cinerea, reproduction, waterbird

\section{INTRODUCTION}

The natural habitat of the Milky Stork Mycteria cinerea is in Southeast Asia - Indonesia, Malaysia, Thailand, Cambodia, and Vietnam (Collar et al., 2001; Iqbal and Hasudungan, 2008; Syamal and Harianto, 2018). It is found mainly on coasts in tidal areas where it nests on mangrove stands and finds food in rice fields or reservoirs, marshes, and wetlands (Collar et al., 2001; Shepherd and Giyanto, 2009; Syamal and Harianto, 2018). Fish, prawns, and crabs are the main diet of the Milky Stork (BirdLife International, 2016). The Milky Stork grows to
95-100 cm tall (Elliott et al., 2019), weighs 2-3 kg, and has a wingspan of 70-100 cm (Zoo Zlín, 2017).

Milky Storks are social animals that live in small flocks, usually 10 to 20 pairs (up to several hundred pairs), often with other species of waterfowl. They nest in large, often multi-species colonies. It builds large nests from branches that are bounded by green vegetation in the treetops, at the height of 2 to 30 metres (Iqbal et al., 2008).

Milky Storks lay between one and four eggs (Zoo Zlín, 2017), and the incubation period is between 27 and 30 days (Hancock et al., 1992; Iqbal et al., 2008). Parents take turns in caring for their offspring 
(Zoo Zlín, 2017). The young birds have light browngrey feathers that are unevenly coloured around the head and neck, and dark-bordered wings (Iqbal et al. 2009; BirdLife International, 2016). Shepherd and Giyanto (2009) and Kin (2019) reported that the colour of the feathers of juvenile Milky Storks is greyish. Offspring aged 20-25 days already see (Iqbal et al., 2008) and at the age of six-to-seven weeks they begin to leave the nest for the first time and learn to fly. By the age of eight weeks, they can fly well, but they are still fed by their parents (Hancock et al., 1992). The average life expectancy of storks is about 20 to 30 years, they reach sexual maturity at the age of 3 and generation interval is 8.4 years (BirdLife International, 2016).

The world population of the Milky Stork is falling sharply. Collar et al. (2001) report that the global number of Milky Storks is 6,100 individuals. Iqbal et al. (2008) and Ismail et al. (2011) estimate the worldwide population of Milky Storks at 5,500 individuals. According to the IUCN Red List, the number of Milky Storks in the wild is estimated at 2,200 individuals, mainly due to a sharp drop in their numbers in Sumatra (BirdLife International, 2016). Baveja et al. (2019) stated that the number of Milky Storks in the wild is only 1,500.

In Malaysia, the population of Milky Storks has declined by more than 90\% over the last 20 years, with over 100 Milky Storks monitored in 1984 and only ten in 2005 (Li et al., 2006; Iqbal et al., 2008), and according to Ismail and Rahman (2016), there are no more than five Milky Storks living in the wild in Malaysia. The greatest threats to the Milky Stork are the disappearance of mangrove stands and habitat due to anthropogenic activities (Ismail and Rahman, 2016) and hunting and egg collection (Iqbal et al., 2008). In Malaysia, a re-introduction programme of the Milky Stork is underway. Between 2007 and 2014, 50 Milky Storks were released under the programme (BirdLife International, 2016).

According to the International Union for the Conservation of Nature, the degree of endangerment of the Milky Stork changed to endangered status in 2013 (BirdLife International, 2016). According to the ISIS world database, Milky Storks are only kept in six zoos in the world (Zoo Zlín, 2017).

This paper aimed to analyse the reproductive characteristics of the Milky Stork raised in captivity.

\section{MATERIALS AND METHODS}

Due to the low number of specimens kept in captivity, only one pair of Milky Stork, which is kept in the Zlín Zoo, was observed over four years; the individual reproductive and related parameters of the Milky Stork were measured.

The Milky Storks were bred seasonally. The transfer to the wintering grounds usually starts in October and is dependent on the ambient temperature. Usually, before morning, temperatures drop below freezing. The inner coops are $5 \mathrm{~m} \times 4 \mathrm{~m} \times 3 \mathrm{~m}$ and are heated to a temperature of $15^{\circ} \mathrm{C}$ to $17^{\circ} \mathrm{C}$. The coops are equipped with branches with a diameter of 5-10 cm for perching and a shallow pool for bathing or feeding. The light regime is controlled by fluorescent lamps and shine ten hours a day. The move to the summer aviary takes place in April and is again dependent on the development of the weather. The outdoor aviary is equipped with a water surface with a water column height of $20 \mathrm{~cm}$ to $40 \mathrm{~cm}$ so that the Milky Storks can use their fishing technique when hunting for food. Also, the aviary is overgrown with low vegetation and trees and is supplemented by branches to provide a wider range of roosting and nesting sites. For better nesting in outdoor aviaries, there were placed on the tree platforms $(60 \mathrm{~cm} \times 60 \mathrm{~cm})$, which served as the basis for building the nest.

After laying, the eggs were counted, measured, and weighed, and then again at regular intervals. The interval between individual weighings was 5-10 days to reduce the disturbance to the nesting activities of the observed pair as much as possible.

During the reporting period, the following indicators were evaluated:

- annual laying rate,

- size and weight of the eggs,

- weight loss of eggs during incubation,

- hatchability and the number of hatchlings,

- hatch weight at hatching.

Statistical evaluation was performed using the statistical program STATISTICA 12.0. The LSD test was used to determine the conclusiveness between individual years of monitoring.

\section{RESULTS AND DISCUSSION}

\section{Evaluation of Milky Stork Laying}

Altogether, 23 eggs of the Milky Stork were evaluated during the monitoring period. In terms of the number of eggs laid, the most successful year for the breeding pair was 2013, when eight eggs were laid. On the contrary, the lowest number of eggs was laid in 2011 and 2014, four eggs (Tab. I).

The average proportion of fertilised eggs over the whole period reached 56.5\% (13 eggs). The lowest proportion of fertilised eggs was in 2012 when only $28.6 \%$ of eggs (2 eggs) were fertilised. The highest proportion of fertilised eggs was recorded in 2014 when $100.0 \%$ of eggs were fertilised (4 eggs). The same proportion of fertilised eggs, 56.5\%, was also found in the Yellow-billed Stork (Rečková et al., 2019). Egg damage only occurred in 2012 at a proportion of $14.3 \%$ (1 egg). In the other three years of observation, egg damage did not occur.

\section{Evaluation of the Size and Weight of Milky Stork Eggs}

During the entire follow-up period, the average Milky Stork egg length was $65.7 \mathrm{~mm}$, the average 
I: Milky Stork laying assessment

\begin{tabular}{cccccc}
\hline \multicolumn{2}{c}{ Factor } & Laying [n] & Fertilised eggs [\%] & Unfertilised eggs [\%] & Damaged eggs [\%] \\
\hline \multicolumn{2}{c}{ Total } & 23 & 56.5 & 39.1 & 4.4 \\
\hline \multirow{4}{*}{ Year } & 2011 & 4 & 75.0 & 25.0 & 0 \\
& 2012 & 7 & 28.6 & 57.1 & 14.3 \\
& 2013 & 8 & 50.0 & 50.0 & 0 \\
& 2014 & 4 & 100.0 & 0 & 0 \\
\hline
\end{tabular}

II: Evaluation of the size and weight of Milky Stork eggs

\begin{tabular}{|c|c|c|c|c|c|c|c|c|c|}
\hline \multirow{2}{*}{\multicolumn{2}{|c|}{ Factor }} & \multirow{2}{*}{$\mathrm{n}$} & \multicolumn{2}{|c|}{ Egg length [mm] } & \multicolumn{2}{|c|}{ Egg width [mm] } & \multicolumn{2}{|c|}{ Egg weight [g] } & \multirow{2}{*}{$\begin{array}{l}\text { Egg shape } \\
\text { index }\end{array}$} \\
\hline & & & $\overline{\mathrm{x}}$ & $s_{x}$ & $\overline{\mathrm{x}}$ & $s_{x}$ & $\overline{\mathrm{x}}$ & $s_{x}$ & \\
\hline & Total & 23 & 65.66 & 2.30 & 47.00 & 1.25 & 79.65 & 5.33 & 1.40 \\
\hline \multirow{4}{*}{ Year } & 2011 & 4 & 64.75 & 2.38 & 47.10 & 1.44 & 78.34 & 7.11 & 1.37 \\
\hline & 2012 & 7 & 65.09 & 1.92 & 47.15 & 1.29 & 79.52 & 6.54 & 1.38 \\
\hline & 2013 & 8 & 65.87 & 2.06 & 46.92 & 1.48 & 80.85 & 5.00 & 1.40 \\
\hline & 2014 & 4 & 67.15 & 3.31 & 46.80 & 0.87 & 78.77 & 2.64 & 1.43 \\
\hline
\end{tabular}

The egg shape index is given by the ratio of the length of the egg and its width and expresses the shape of an egg.

egg width was $47.0 \mathrm{~mm}$, and the average egg weight reached $79.7 \mathrm{~g}$ (Tab. II).

When comparing the size parameters of Milky Stork eggs with the other stork eggs, the average length of the Milky Stork eggs was $2.9 \mathrm{~mm}$ shorter than that of the Painted Stork (Rečková et al., 2017) and $0.4 \mathrm{~mm}$ shorter than that of the Yellow-billed Stork (Rečková et al., 2019). The difference in egg width between different species of stork was not pronounced. The Milky Stork egg was $0.6 \mathrm{~mm}$ wider than that of the Painted Stork (Rečková et al., 2017) and the width of the Yellow-billed Stork eggs was almost identical (Rečková et al., 2019). When comparing the size of the Milky Stork eggs with the Storm's Stork from the same family, the Milky Stork eggs were $5.5 \mathrm{~mm}$ longer and $5.1 \mathrm{~mm}$ wider than that of the Storm's Stork (Danielsen et al., 1997). The weight of the Milky Stork's eggs with other storks was almost identical to $79.8 \mathrm{~g}$ of Painted Stork and $80.5 \mathrm{~g}$ of Yellow-billed Stork (Rečková et al., 2017; Rečková et al., 2019). Regarding the index of the shape of the egg, the Milky Stork's eggs and the Yellow-billed Stork's eggs were almost identical, namely 1.40 and 1.41 (Rečková et al., 2019), and slightly higher in the Painted Stork, namely 1.48 (Rečková et al., 2017).

The longest egg was found in 2014 when the average egg length reached $67.2 \mathrm{~mm}$. On the contrary, the shortest eggs were obtained in 2011 , when the average egg length was $64.8 \mathrm{~mm}$, which is $2.4 \mathrm{~mm}$ less than that in 2014. There were no statistically significant differences in egg length between the individual years of monitoring.

In terms of egg width, the widest egg occurred in 2012 and measured $47.2 \mathrm{~mm}$. The narrowest eggs were produced in 2014 when their width was $0.4 \mathrm{~mm}$ narrower than those in 2012, and their average value reached $46.8 \mathrm{~mm}$. There were no statistically significant differences in egg width among the eggs from individual years.

Again, it was confirmed that in the year when the eggs were the longest (2014), they were also the narrowest. There was very little variation in the average width of Milky Stork eggs in individual years, so it was not confirmed that the eggs that were the widest would also be the shortest. This is also documented by the egg shape index, which was the highest in 2014, namely 1.43, and the lowest in 2011 when it reached 1.37, and immediately after that in 2012, when its value was only higher by 0.01 , namely 1.38 .

Regarding the weight of the eggs in each year of monitoring, the eggs with the highest weight were laid in 2013, when their average weight was $80.9 \mathrm{~g}$. On the contrary, the lowest weight was reached in 2011, when their average weight was $2.5 \mathrm{~g}$ lower than those laid in 2013. Also, there were no statistically significant differences in egg weight during the individual years of monitoring.

\section{Evaluation of Egg Weight Loss During Incubation}

Throughout the observation period, the average weight loss of the eggs during their incubation was $8.4 \mathrm{~g}$. The average daily weight loss of eggs during their incubation was $0.4 \mathrm{~g}$ (Tab. III).

When comparing the weight loss of eggs during incubation with other species of stork, the weight loss was lowest in the Yellow-billed Stork, at $5.6 \mathrm{~g}$ (Rečková et al., 2019) and the highest was the Painted Stork, at 9.9 g (Rečková et al., 2017). 
III: Weight loss of Milky Stork eggs during incubation

\begin{tabular}{|c|c|c|c|c|c|c|}
\hline \multirow{2}{*}{\multicolumn{2}{|c|}{ Factor }} & \multirow{2}{*}{$\mathrm{n}$} & \multicolumn{2}{|c|}{ Total weight loss [g] } & \multicolumn{2}{|c|}{ Average daily weight loss [g] } \\
\hline & & & $\overline{\mathrm{x}}$ & $\mathrm{s}_{\mathrm{x}}$ & $\overline{\mathrm{x}}$ & $s_{x}$ \\
\hline & & 22 & 8.43 & 3.03 & 0.36 & 0.07 \\
\hline \multirow{4}{*}{ Year } & 2011 & 4 & $7.67^{\mathrm{a}}$ & 0.66 & $0.33^{\mathrm{a}}$ & 0.01 \\
\hline & 2012 & 6 & 8.03 & 4.85 & $0.32^{\mathrm{a}}$ & 0.10 \\
\hline & 2013 & 8 & 8.03 & 2.18 & 0.37 & 0.05 \\
\hline & 2014 & 4 & $10.72^{\mathrm{b}}$ & 0.49 & $0.43^{b}$ & 0.02 \\
\hline
\end{tabular}

$\mathrm{p} \leq 0.05: \mathrm{a}-\mathrm{b}$

Regarding egg weight loss during incubation over the years of monitoring, the average egg weight loss during incubation was the lowest in 2011 (7.7 g). The highest average egg weight loss during incubation was in 2014 (10.7 g), which is $3.1 \mathrm{~g}$ more than in 2011. There was a statistically significant difference between 2011 and 2014 regarding weight loss.

In 2012, the average daily weight loss during egg incubation reached the lowest value of $0.3 \mathrm{~g}$. The highest average daily weight loss during egg incubation was in 2014 (0.4 g), as well as the total weight loss during egg incubation. The average daily weight loss of eggs during incubation showed statistically significant differences between 2014, when the average daily weight loss was the highest, and in 2011 and 2012, when the average daily weight loss was statistically significantly lower.

\section{Evaluation of the Number of Hatched and Reared Milky Stork Hatchlings}

During the whole monitoring period, the average hatching rate of all laid eggs was $56.5 \%$. The average hatching rate of fertilised eggs reached $100.0 \%$ during the entire monitoring period. A total of 13 Milky Stork hatchlings hatched during the monitoring period. A total of five individuals were bred during the monitoring period (Tab. IV).

In terms of hatching of the laid eggs, the most successful year was 2014, when the hatching percentage reached $100.0 \%$ of all laid eggs. The least successful year was 2012, when the average hatching rate reached $28.6 \%$ of all eggs laid.

The maximum hatching rate, $100.0 \%$ hatching from fertilised eggs, was reached in all years of the monitoring period for Milky Storks.

Regarding the number of hatched chicks, the most successful years were 2013 and 2014, when four chicks were hatched. The least successful year was 2012, when only two chicks hatched. In the Negara Zoo in Malaysia in the years 1990-1996, a total of 47 Milky Storks hatched; the minimum number of hatched chicks in one year was three and the maximum number of chicks was nine. In 2002 and 2005, 22 and 17 chicks were hatched, respectively (Ismail et al., 2011).

In the Zlín Zoo the most successful year regarding the number of chicks hatched was 2014 when a total of four Milky Stork chicks hatched, and the success rate of rearing chicks was 100\% that year. On the contrary, the least successful years concerning the number of reared chicks were 2012 and 2013, when unfortunately no chicks were bred. Regarding the breeding of Milky Stork chicks, Ismail et al. (2011) state that the breeding success rate is $48 \%$ in Negara Zoo.

Over the entire monitoring period, the average weight of chicks on hatching day was $55.7 \mathrm{~g}$. The average weight of Milky Stork hatchlings is $1.4 \mathrm{~g}$ lower than that of the Painted Stork hatchlings (Rečková et al., 2017) and $2.5 \mathrm{~g}$ lower compared to Yellow-billed chicks (Rečková et al., 2019).

IV: Number of hatched and reared Milky Stork hatchlings

\begin{tabular}{|c|c|c|c|c|c|c|}
\hline \multirow{2}{*}{\multicolumn{2}{|c|}{ Factor }} & \multicolumn{2}{|c|}{ Hatchability [\%] } & \multirow{2}{*}{ Hatched chicks [n] } & \multirow{2}{*}{ Reared chicks [n] } & \multirow{2}{*}{$\begin{array}{c}\text { Weight on } \\
\text { hatching day [g] }\end{array}$} \\
\hline & & of all laid eggs & of fertilised eggs & & & \\
\hline & Total & 56.52 & 100.00 & 13 & 5 & $55.65 \pm 3.15$ \\
\hline \multirow{4}{*}{ Year } & 2011 & 75.00 & 100.00 & 3 & 1 & $56.85 \pm 2.49$ \\
\hline & 2012 & 28.57 & 100.00 & 2 & 0 & $57.06 \pm 3.54$ \\
\hline & 2013 & 50.00 & 100.00 & 4 & 0 & $56.78 \pm 3.16$ \\
\hline & 2014 & 100.00 & 100.00 & 4 & 4 & $52.93 \pm 2.64$ \\
\hline
\end{tabular}




\section{CONCLUSION}

A total of 23 Milky Stork eggs from one parent pair were evaluated throughout the monitoring period. The average proportion of fertilised eggs was 56.5\% (13 eggs). The following parameters of Milky Stork eggs were ascertained: the average egg length was $65.7 \mathrm{~mm}$, the average egg width was $47.0 \mathrm{~mm}$, and the average egg weight was $79.7 \mathrm{~g}$. During the entire monitoring period, the mean weight loss of Milky Stork eggs during their incubation was $8.4 \mathrm{~g}$. The average weight loss of eggs during the incubation was in the range of $7.7 \%$ to $10.7 \%$. The average hatching rate of all laid eggs was 56.5\% for the Milky Stork, and the average hatching rate for fertilised eggs was 100.0\%. For the monitored Milky Stork pair, 13 chicks were hatched in the four years of monitoring while five of those were successfully reared.

Acknowledgements

We gratefully acknowledge the cooperation of Lešná Zoo in the Czech Republic.

\section{REFERENCES}

BAVEJA, P., TANG, Q., LEE, J. G. H. and RHEINDT, F. E. 2019. Impact of genomic leakage on the conservation of the endangered Milky Stork. Biological Conservation, 229(35): 59-66.

BIRDLIFE INTERNATIONAL. 2016. Mycteria cinerea. The IUCN Red List of Threatened Species. [Online]. Available at: www.iucnredlist.org/species/22697651/93627701 [Accessed: 2021, March 10].

COLLAR, N. J., ANDREEV, A. V., CHAN, S., CROSBY, M. J., SUBRAMANYA, S. and TOBIAS, J. A. 2001. Threatened birds of Asia: The BirdLife International Red Data Book. Cambridge: BirldLife International.

DANIELSEN, F., KADARISMAN, R., SKOV, H., SUWARMAN, U. and VERHEUGT, W. J. M. 1997. The Storm's Stork Ciconia stormi in Indonesia: Breeding biology, population and conservation. Ibis, 139(1): 67-75.

ELLIOTT, A., GARCIA, E. F. J. and BOESMAN, P. 2019. Milky Stork (Mycteria cinerea). In: DEL HOYO, J., ELLIOTT, A., SARGATAL, J., CHRISTIE, D. A. and DE JUANA, E. (Eds.). Birds of the World. Ithaca, NY: Cornell Lab of Ornithology.

HANCOCK, J., KUSHLAN, J. A. and KAHL, M. P. 1992. Storks, ibises and spoonbills of the world. London: Academic Press.

ISMAIL, A. and RAHMAN, F. 2016. Current Status of the Milky Stork Re-introduction Programme in Malaysia and Its Challenges. Tropical Life Sciences Research, 27(2): 13-24.

ISMAIL, A., RAHMAN, F., KIN, D. K. S., RAMLI, M. N. H. and NGAH, M. 2011. Current status of the Milky Stork captive breeding program in Zoo Negara and its importance to the Stork population in Malaysia. Tropical Natural History, 11(1): 75-80.

IQBAL, M. and HASUDUNGAN, F. 2008. Observations of Milky Stork Mycteria cinerea during 2001-2007 in South Sumatra province, Indonesia. BirdingASIA, 9: 97-99.

IQBAL, M., RIDWAN, A., TAKARI, F. and MULYONO, H. 2008. Rediscovery of a Milky Stork Mycteria cinerea breeding colony in South Sumatra province, Indonesia. BirdingASIA: 62-66.

IQBAL, M., TAKARI, F., MULYONO, H. and RASAM. 2009. A note on the breeding success of Milky Stork Mycteria cinerea in 2008, South Sumatra province, Indonesia and more on its diet. BirdingASIA, 11: 73-74.

IQBAL, M., MULYONO, H., RIWAN, A. and TAKARI, F. 2012. An alarming decrease in the Milky Stork Mycteria cinerea population on the east coast of South Sumatra province, Indonesia. BirdingASIA, 18: 68-70.

KIN, D. K. S. 2019. Captive Breeding of Milky Storks at Zoo Negara, Malaysia. [Online]. Available at: zoonegaramalaysia.my/RPMilky Storks.pdf [Accessed: 2021, April 21].

LI, Z. W. D., HAWA, Y. H. S., HOWES, J. and ILIAS, R. 2006. Status overview and recommendations for the conservation of Milky Stork Mycteria cinerea in Malaysia: Final Report of the 2004/2006 Milky Stork Field Surveys in the Matang Mangrove Forest, Perak, Malaysia. Peninsular Malaysia: Wetlands International and the Department of Wildlife and National Parks.

REČKOVÁ, Z., FILIPČÍK, R., MÁCHAL, L., KŘIVÁNEK, I., NEVRKLA, P. and HORSKÝ, R. 2017. Analysis of reproductive traits in the painted stork (Mycteria leucocephala). Acta Universitatis agriculturae et silviculturae Mendelianae Brunensis, 65(5): 1601-1605.

REČKOVÁ, Z., FILIPČÍK, R., MÁCHAL, L. and HORSKÝ, R. 2019. Analysis of reproduction indicators of the yellow-billed stork (Mycteria ibis). Acta Universitatis agriculturae et silviculturae Mendelianae Brunensis, 67(1): 155-161.

SHEPHERD, C. R., GIYANTO, G. 2009. Observations of Milky Storks Mycteria cinerea in Percut, North Sumatra, Indonesia. BirdingASIA, 11: 70-72. 
SYAMAL, F. M. and HARIANTO. S. P. 2018. Study of the Milky Stork Bird (Mycteria cinerea) Population in Rawa Pacing, Kibang Pacing Village, Menggala Timur Sub-District, Menggala Timur Regency, Lampung Province. Journal Sylva Lestari, 6(2): 1-6.

ZOO ZLÍN. 2017. Nesyt bílý (Mycteria cinerea). Zoo Zlin. [Online]. Available at: www.zoozlin.eu/nesytbily [Accessed: 2021, May 6]. 